\title{
СТРУКТУРА И СВОЙСТВА ПЛЕНОК ZnSe, ПОЛУЧЕННЫХ МЕТОДОМ ЭЛЕКТРОХИМИЧЕСКОГО ОСАЖДЕНИЯ
}

\author{
(C) 2016 г. Д. С. Софронов*, В. В. Стариков**, 1, Т. В. Новикова**, Е. А. Вакслер*, \\ П. В. Матейченко***, А. М. Лебединский ${ }^{* * *}$, Я. А. Бондаренко*, Д. А. Гаман** \\ *НТК “Институт монокристаллов” НАН Украины, Украина, 61001 Харьков, пр. Ленина, 60 \\ **Национальный технический университет “ХПИ”, Украина, 61002 Харьков, ул. Фрунзе, 21 \\ ***Институт монокристаллов НАН Украины, Украина, 61001 Харьков, пр. Ленина, 60 \\ ****Национальный исследовательский Томский политехнический университет, \\ Россия, 634050, Томск, пр. Ленина, 30 \\ ${ }^{1}$ e-mail: sofronov@isc.kharkov.com \\ Поступила в редакцию 30.11.2015 г.
}

\begin{abstract}
Методом электрохимического осаждения в щелочном растворе получены пленки ZnSe со структурой сфалерита, сформированные сферическими частицами размером 0.5-1.0 мкм (при $J_{\kappa}=0.05 \mathrm{~A} / \mathrm{cm}^{2}$ ). Пленки характеризуются $p$-типом проводимости с удельным электрическим сопротивлением (1.5$6.8) \times 10^{6}$ Ом м. Величина ширины запрещенной зоны варьирует в пределах 2.37-2.55 эВ.
\end{abstract}

Ключевые слова: пленки, селенид цинка, электрохимическое осаждение

DOI: $10.7868 / \mathrm{S} 0002337 \mathrm{X} 16110178$

\section{ВЕДЕНИЕ}

Пленки селенида цинка $\mathrm{ZnSe}$ используют для изготовления светоизлучающих устройств в голубой области спектра, в качестве функциональных слоев детекторов рентгеновских сканеров, компьютерных томографов и солнечных элементов [1-4]. Основным методом получения пленок $\mathrm{ZnSe}$ является термическое осаждение из газовой фазы на подложку, требующее специального оборудования.

В настоящее время активно разрабатываются способы получения пленок из растворов. В частности, предложено электрохимическое получение пленок селенида цинка. В основном осаждение проводится из кислых электролитов при $\mathrm{pH} 2.0-2.5$ и температуре около $70^{\circ} \mathrm{C}$ [5-7].

Ранее получены пленки селенида цинка при взаимодействии оксида цинка с селеном в растворах 1-5 M NaOH $[8,9]$. Показано, что при всех использованных режимах осаждения формируется сфалеритная модификация $\mathrm{ZnSe}$, с размером частиц от 0.2 до 0.9 мкм в зависимости от условий осаждения. Оптимальная концентрация шелочи для получения пленок составила $3 \mathrm{M}$, время осаждения 1 ч. При этом на процесс формирования пленок существенное влияние оказывал восстановитель (гидразин), что затрудняло управление процессом получения пленки. Использование постоянного электрического тока вместо восстановителя позволило бы повысить управляемость процессом формирования пленок. Однако в литературе отсутствуют сведения о получении пленок селенида цинка из щелочных растворов.

Цель работы - изучение формирования пленок $\mathrm{ZnSe}$ в щелочном растворе электрохимическим способом.

\section{ЭКСПЕРИМЕНТАЛЬНАЯ ЧАСТЬ}

Для синтеза пленок $\mathrm{ZnSe}$ использовали $\mathrm{Se}$ (“х. ч.”), $\mathrm{NaOH}$ (“х. ч.”). Растворы готовили на дистиллированной воде. Пленки ZnSe формировали на катоде, изготовленном из оцинкованного листа 0.4 мм размером $2 \times 4 \mathrm{~cm}$. Анод - нержавеющая сталь марки $12 \mathrm{X} 18 \mathrm{H} 10 \mathrm{~T}$ размером $4 \times 4 \mathrm{~cm}$. Перед получением пленок оцинкованную сталь обезжиривали в $1 \mathrm{M}$ растворе $\mathrm{NaOH}$ при $60^{\circ} \mathrm{C}$ в течение 15 мин, промывали дистиллированной водой и высушивали при комнатной температуре в течение 1 ч. Нержавеющую сталь предварительно травили в $30 \%$-ной азотной кислоте, после обезжиривали в $1 \mathrm{M}$ растворе $\mathrm{NaOH}$ при $60^{\circ} \mathrm{C}$ в течение 30 мин, промывали дистиллированной водой и высушивали при комнатной температуре в течение 1 ч.

Селенирование осуществляли в электролите следующего состава: $3 \mathrm{M} \mathrm{NaOH}, 0.5 \mathrm{M} \mathrm{Se}$. Объем электролита -80 мл. Температура раствора $80^{\circ} \mathrm{C}$. Время селенирования $(\tau)$ - от 5 до 60 мин. Пленки получали в гальваностатическом режиме. Катодную плотность тока $\left(J_{k}\right)$ варьировали от 0.05 до 
$I$, отн. ед.

(a)

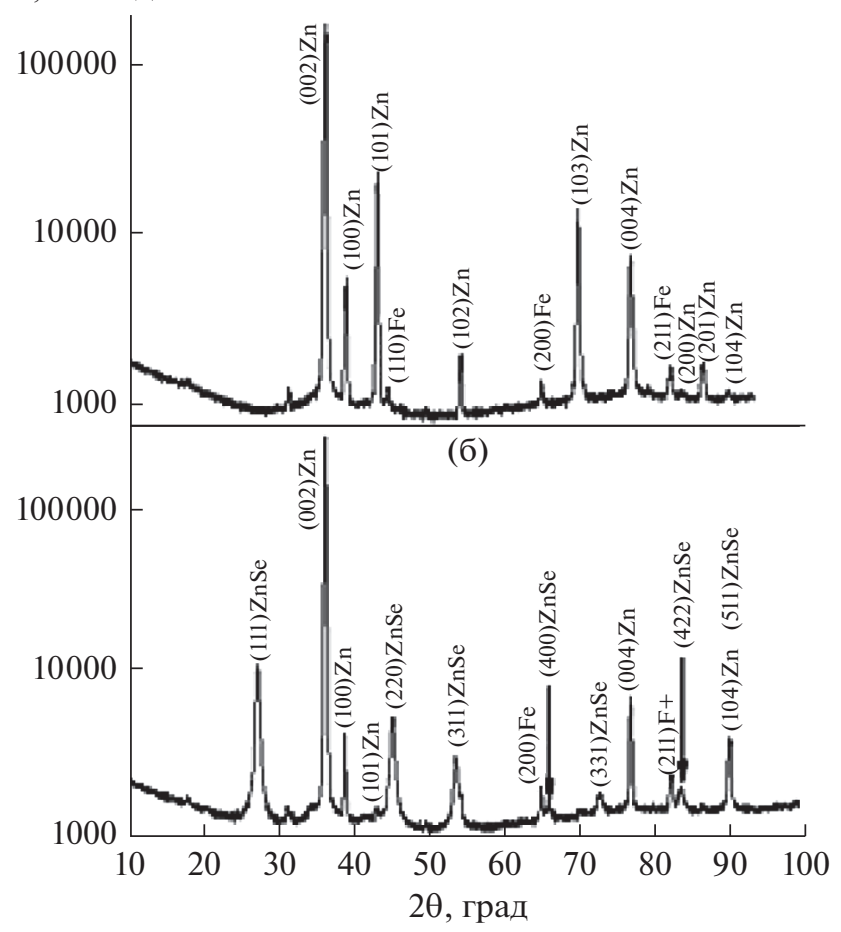

Рис. 1. Дифрактограммы подложки (а) и подложки с пленкой (б), полученной при $J_{k}=0.15 \mathrm{~A} / \mathrm{cm}^{2}$ в течение 5 мин.

$0.25 \mathrm{~A} / \mathrm{cm}^{2}$. По завершении процесса осаждения подложку с пленкой вынимали из раствора, промывали несколько раз в дистиллированной воде, спирте и сушили при комнатной температуре в течение 1 ч.

Кристаллическую структуру осажденных пленок анализировали методом рентгеновской дифрактометрии в геометрии Брэгга-Брентано с графитовым монохроматором на первичном пучке при $\mathrm{Cu} K_{\alpha}$-излучении. Фазовый анализ структуры пленок проводили путем сопоставления межплоскостных расстояний и относительных интенсивностей рентгеновских пиков от исследуемых образцов и эталона по данным JCPDS [10].

ИК-спектры получали на Фурье ИК-спектрофотометре Spectrum One (Perkin Elmer) в таблетках KBr. Морфологию пленок исследовали с использованием сканирующего микроскопа JSM-6390LV. Толщину пленок контролировали с помощью интерферометра Линника. Спектральные зависимости коэффициентов отражения $R(\lambda)$ конденсатов измеряли с помощью спектрофотометра СФ-2000-02 с приставкой зеркального и диффузного отражения СФО-2000. Тип проводимости синтезированных пленок определяли по знаку термо-ЭДС с использованием термозонда.

\section{РЕЗУЛЬТАТЫ И ОБСУЖДЕНИЕ}

Получение пленок. В щелочном растворе при нагревании селен диспропорционирует с образованием селенит и селенат ионов, а цинковое покрытие растворяется:

$$
\begin{gathered}
3 \mathrm{Se}+6 \mathrm{OH}^{-} \leftrightarrow 2 \mathrm{Se}^{2-}+\mathrm{SeO}_{3}^{2-}+3 \mathrm{H}_{2} \mathrm{O}, \\
\mathrm{Zn}+2 \mathrm{OH}^{-}+2 \mathrm{H}_{2} \mathrm{O} \rightarrow\left[\mathrm{Zn}(\mathrm{OH})_{4}\right]^{2-}+\mathrm{H}_{2} \uparrow .
\end{gathered}
$$

На катоде ионы $\mathrm{SeO}_{3}^{2-}$ восстанавливаются по реакции [11]:

$$
\mathrm{SeO}_{3}^{2-}+6 \mathrm{e}+3 \mathrm{H}_{2} \mathrm{O} \rightarrow \mathrm{Se}^{2-}+6 \mathrm{HO}^{-} \text {. }
$$

В прикатодном слое происходит образование частиц селенида цинка при взаимодействии $\mathrm{Se}^{2-}$ с $\left[\mathrm{Zn}(\mathrm{OH})_{4}\right]^{2-}$, которые впоследствии сорбируются на поверхности электрода с образованием пленки:

$$
\left[\mathrm{Zn}(\mathrm{OH})_{4}\right]^{2-}+\mathrm{Se}^{2-} \rightarrow \mathrm{ZnSe} \downarrow+4 \mathrm{OH}^{-} .
$$

При отсутствии катодной поляризации процесс образования частиц селенида цинка происходит в объеме реакционной смеси за счет взаимодействия $\left[\mathrm{Zn}(\mathrm{OH})_{4}\right]^{2-}$ ионов с ионами $\mathrm{Se}^{2-}$, образовавшимися по реакции (1). В результате на дно реакционного сосуда осаждается порошок селенида цинка [12]. Кроме того, в системе могут протекать побочные процессы [11]:

$$
\begin{gathered}
2 \mathrm{HSe}^{-}+0.5 \mathrm{O}_{2} \rightarrow 2 \mathrm{Se}+\mathrm{H}_{2} \mathrm{O}, \\
2 \mathrm{HSe}^{-}+\mathrm{SeO}_{3}^{2-}+\mathrm{H}_{2} \mathrm{O} \rightarrow 3 \mathrm{Se}+4 \mathrm{OH}^{-}, \\
2 \mathrm{H}_{2} \mathrm{O}+2 \mathrm{e} \rightarrow \mathrm{H}_{2} \uparrow+2 \mathrm{OH}^{-} .
\end{gathered}
$$

Образующийся по реакциям (5) и (6) селен вновь диспропорционирует в щелочном растворе по реакции (1).

В результате селенирования получены пленки желтого цвета с красноватым оттенком. На рис. 1 представлены дифрактограммы подложки до и после формирования пленки при $J_{k}=0.15 \mathrm{~A} / \mathrm{cm}^{2}$ в течение 5 мин. На дифрактограмме подложки присутствуют рефлексы отражения, соответствующие цинковому покрытию, а также слабые рефлексы отражения, соответствующие железной основе (рис. 1а). После селенирования (рис. 1б) на дифрактограмме дополнительно появились рефлексы отражений, которые могут быть идентифицированы как селенид цинка со структурой сфалерита. Варьирование условий селенирования $\left(J_{k}, \tau\right)$ не оказало влияния на вид дифрактограммы. Во всех случаях наблюдалось формирование пленки со структурой сфалерита. С увеличением плотности тока более $0.25 \mathrm{~A} / \mathrm{cm}^{2}$ происходит интенсивное выделение водорода на катоде, при котором формирование пленки затруднено.

ИК-спектры пленок представлены на рис. 2. В ИК-спектрах пленок, полученных при $J_{k}=$ $=0.05 \mathrm{~A} / \mathrm{cm}^{2}$ (рис. 2, спектры 1-3), независимо от 


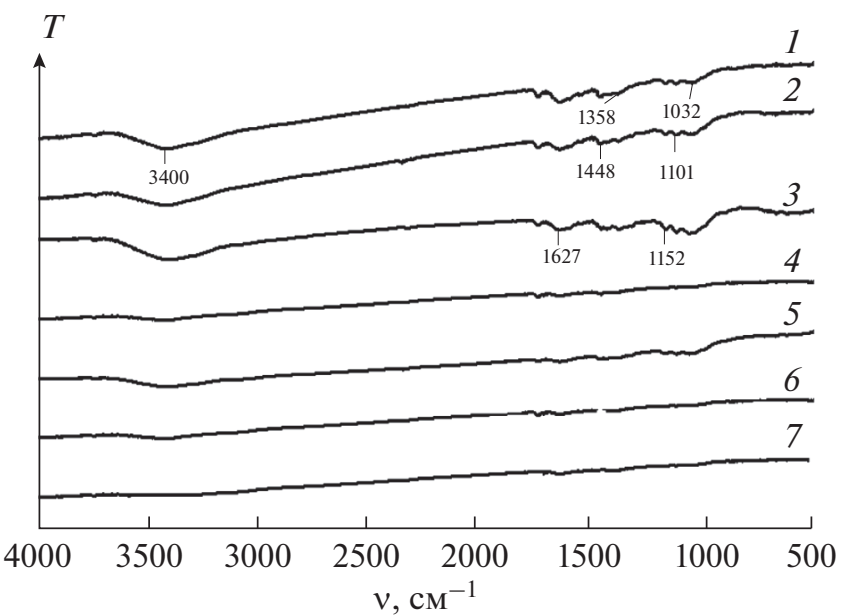

Рис. 2. ИК-спектры пленок, полученных при плотности тока $\left(\mathrm{A} / \mathrm{cm}^{2}\right)$ и времени селенировани (мин): 1 $0.05,5 ; 2-0.05,10 ; 3-0.05,40 ; 4-0.15,5 ; 5-0.15,40$; $6-0.25,5 ; 7-0.25,20$.

времени селенирования наблюдаются полосы поглощения, соответствующие 3400 и $1627 \mathrm{~cm}^{-1}$ и связанные, соответственно, с валентными и деформационными колебаниями молекул воды, адсорбиро- ванных на поверхности частиц селенида цинка. Полосы поглощения 1448 и $1358 \mathrm{~cm}^{-1}$ связаны с колебаниями иона $\mathrm{CO}_{3}^{2-}$ [9], а полосы 1101 и $1032 \mathrm{~cm}^{-1}$ - $\mathrm{HCO}_{3}^{-}[13]$, присутствие которого в растворе селенирования обусловлено процессами частичной карбонизации исходной щелочи в процессе ее хранения. В ИК-спектрах пленок, полученных при плотности тока $0.15 \mathrm{~A} / \mathrm{cm}^{2}$ и выше (рис. 2, спектры 4-7), полос поглощения практически не наблюдается, что может свидетельствовать о высокой чистоте синтезированных пленок.

Микрофотографии пленок представлены на рис. 3. В случае малых плотностей тока (рис. 3a) пленки формируются сферическими частицами размером 0.5-1 мкм и практически не содержат макродефектов. Увеличение времени селенирования до 20 мин вначале приводит к появлению крупных частиц до 3 мкм (рис. 3б), а при селенировании более 40 мин в пленке формируются макродефекты в виде трещин. В случае увеличения плотности тока до $0.15 \mathrm{~A} / \mathrm{cm}^{2}$ (рис. 3г, 3д) наблюдается развитие рельефа поверхности. При селенировании в течение 60 мин (рис. 3е) пленка
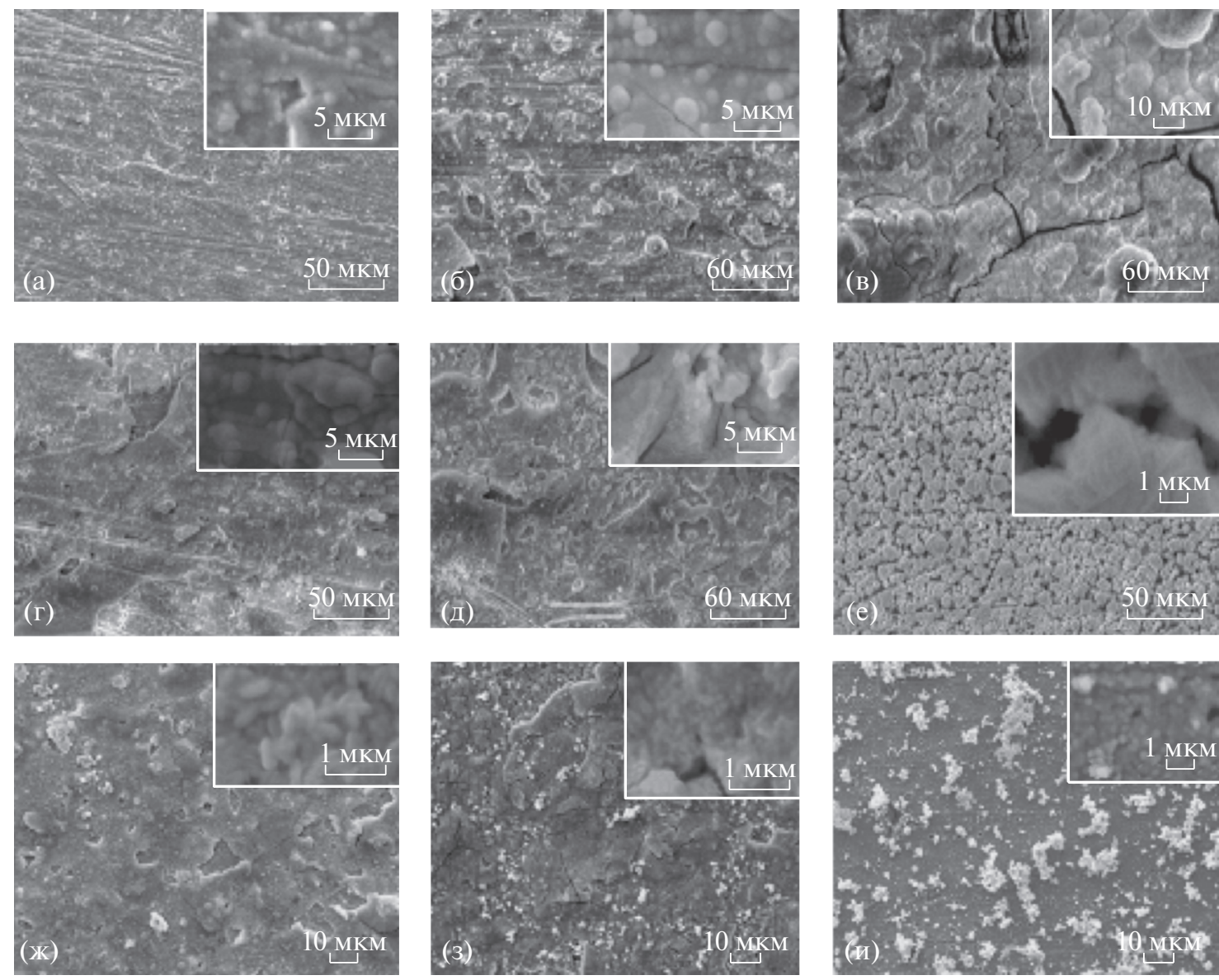

Рис. 3. Микрофотографии поверхности пленок, полученных при плотности тока (А/см²) и времени селенирования

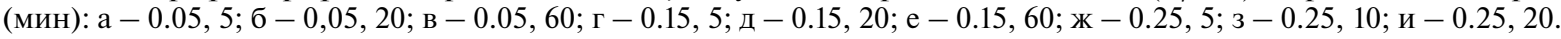




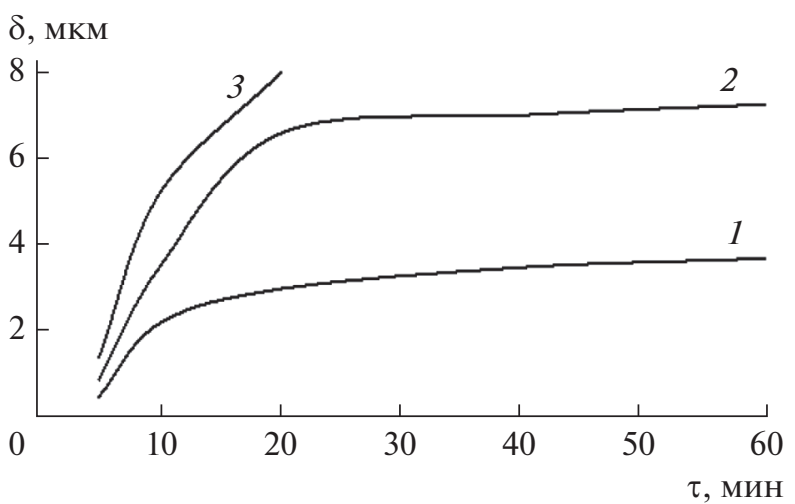

Рис. 4. Зависимости толщины пленки от времени селенирования при плотности тока $\left(\mathrm{A} / \mathrm{cm}^{2}\right): 1-0.05$; $2-0.15 ; 3-0.25$.

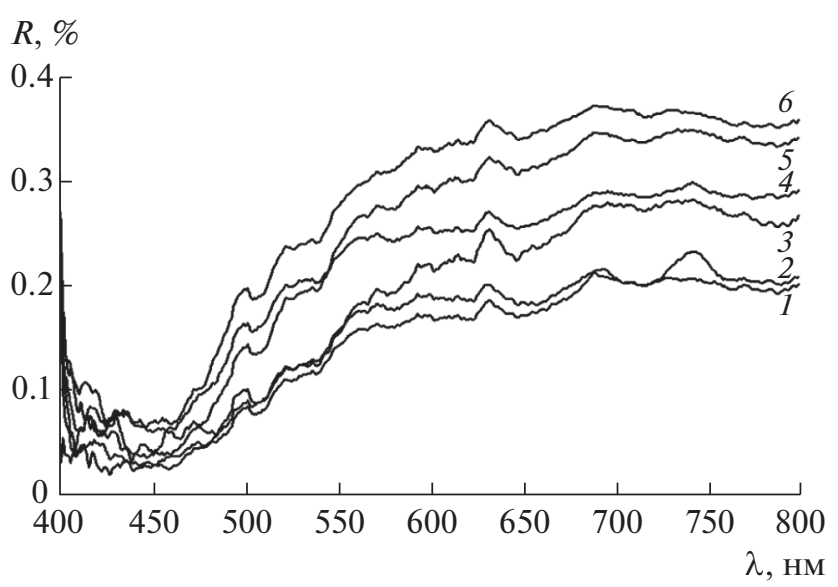

Рис. 5. Спектры отражения пленок, полученных при плотности тока $\left(\mathrm{A} / \mathrm{cm}^{2}\right)$ и времени селенирования (мин): $1-0.05,5 ; 2-0.05,60 ; 3-0.15,5 ; 4-0.15,60$, $5-0.25,5 ; 6-0.25,20$.

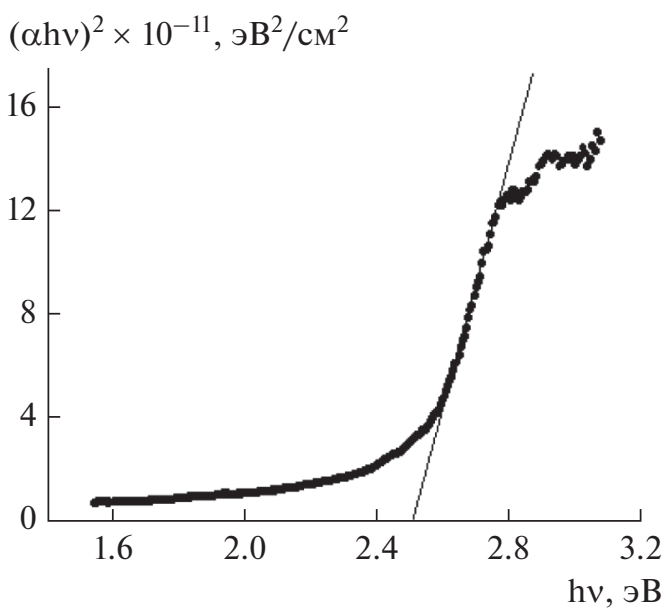

Рис. 6. Расчет ширины запрешенной зоны пленки, полученной при $J_{k}=0.05 \mathrm{~A} / \mathrm{cm}^{2}$ в течение 5 мин. формируется частицами в виде крупных пластин размером до нескольких десятков микрон с развитой системой пор диаметром несколько микрон. Повышение плотности тока до $0.25 \mathrm{~A} / \mathrm{cm}^{2}$ способствует формированию пленок агломерированными частицами в форме вытянутых зерен до 1 мкм (рис. 3ж). При этом с повышением длительности селенирования до 20 мин (рис. 3и) на поверхности пленки наблюдается формирование крупных агломерированных островков. Дальнейшее увеличение времени селенирования при плотности тока $0.25 \mathrm{~A} / \mathrm{cm}^{2}$ приводит к отслаиванию отдельных участков пленки от подложки.

Толщина получаемых пленок растет с увеличением времени осаждения и плотности тока (рис. 4). При этом можно выделить два участка зависимости: на первом этапе происходит интенсивный рост толщины пленки (осаждение до 10 мин при $J_{k}=0.05 \mathrm{~A} / \mathrm{cm}^{2}$ и до 20 мин при $\left.J_{k}=0.15 \mathrm{~A} / \mathrm{cm}^{2}\right) ;$ на втором этапе прирост толщины пленки существенно замедляется, что связано с затруднением диффузии цинкат- и селенид-ионов через пленку по мере увеличения ее толщины [14].

Оптические и электрические свойства. Для всех синтезированных пленок сняты спектры отражения $R(\lambda)$ (рис. 5). Характер кривых практически одинаков: все образцы демонстрировали снижение уровня отражения в области спектра 450-550 нм, связанное с поглощением световых квантов при межзонных переходах. Как видно, при увеличении плотности тока или времени осаждения формируется более плотная сплошная пленка, имеющая бо́льшую отражательную способность поверхности.

По экспериментальным данным рассчитывали спектральные зависимости коэффициента поглощения $\alpha(\lambda)$. Все полученные зависимости перестраивали в координатах $(\alpha h v)^{2}-\mathrm{h} v$ в предположении, что в исследуемых полупроводниковых пленках реализовывались прямозонные переходы. Поскольку все рассчитанные кривые не имели существенных различий между собой, на рис. 6 приведена наиболее характерная из них. Пересечение касательной, проведенной к экспериментальной кривой, и горизонтали, выходящей из нулевого значения поглощения, определяло значение оптической ширины запрещенной зоны полупроводниковой пленки ZnSe. Найденные значения ширины запрещенной зоны для всех пленок изменялись в пределах от 2.37 до 2.55 эВ, что хорошо согласуется с литературными данными (2.45-2.65 эВ) для пленок $\mathrm{ZnSe}$, полученными с помощью других методик.

Анализ полярности термо-ЭДС показал, что все пленки, осажденные при концентрации щелочи $3 \mathrm{M}$ и селена $0.5 \mathrm{M}$, обладали проводимостью $p$-типа. Измерение электрического сопротивления пленок проводили путем сканирования 
Зависимость удельного электрического сопротивления пленок $\mathrm{ZnSe}$ от плотности тока в ячейке и времени осаждения

\begin{tabular}{c|c|c|c|c|c}
\hline \multirow{2}{*}{$J_{k}, \mathrm{~A} / \mathrm{cм}^{2}$} & \multicolumn{5}{|c}{$\rho$, Ом м } \\
\cline { 2 - 6 } & 5 мин & 10 мин & 20 мин & 40 мин & 60 мин \\
\hline 0.05 & $2.3 \times 10^{5}$ & $3.0 \times 10^{6}$ & $2.3 \times 10^{6}$ & $3.8 \times 10^{6}$ & $3.3 \times 10^{6}$ \\
0.15 & $2.7 \times 10^{6}$ & $6.8 \times 10^{5}$ & $1.8 \times 10^{6}$ & $2.3 \times 10^{6}$ & $1.5 \times 10^{6}$ \\
0.25 & $6.8 \times 10^{6}$ & $1.9 \times 10^{6}$ & $2.8 \times 10^{6}$ & - & - \\
\hline
\end{tabular}

точечным прижимным зондом различных участков поверхности. Сопротивление незначительно изменялось для разных точек поверхности каждого из образцов, что свидетельствовало об их однородности. Рассчитанные значения удельного электросопротивления пленок $\mathrm{ZnSe}$ представлены в таблице. Установлено, что с ростом времени селенирования и плотности тока наблюдается незначительное снижение сопротивления пленок, что, вероятно, связано с увеличением числа макродефектов в их структуре.

\section{ЗАКЛЮЧЕНИЕ}

Методом электрохимического осаждения из щелочных растворов сформированы пленки ZnSe со структурой сфалерита и проводимостью $p$-типа на поверхности цинкового покрытия. При плотности тока $0.05 \mathrm{~A} / \mathrm{cm}^{2}$ пленки были сформированы сферическими частицами с размерами 0.5-1 мкм и не содержали макродефектов. Увеличение времени селенирования и плотности тока приводило к укрупнению частиц и увеличению числа макродефектов в пленке. Однако наиболее чистые по примесному составу пленки формировались при плотности тока $0.15 \mathrm{~A} / \mathrm{cm}^{2}$ и выше.

Независимо от условий селенирования пленки $\mathrm{ZnSe}$ характеризовались величиной запрещенной зоны 2.37-2.55 эВ. Удельное сопротивление пленок варьировало в пределах (1.5-6.8) × 106 Ом м. С ростом времени селенирования и повышением плотности тока удельное сопротивление понижалось из-за увеличения количества макродефектов в пленках.

\section{СПИСОК ЛИТЕРАТУРЫ}

1. Vij D.R. Luminescence of Solids. N.Y.: Plenum Press, 1998. $221 \mathrm{p}$.

2. Gaysinskiy V., Singh B., Ovechkina L., Miller S., Thacker S., Nagarkar $V$. Luminescence Properties and Morphology of ZnSe:Te Films // IEEE Trans. Nucl. Sci. 2008. V. 55. № 3. P. 1556-1560.
3. Андреев В.М., Грилихес В.А., Румянцев В.А. Фотоэлектрическое преобразование концентрированного солнечного излучения. Л.: Наука, 1989. 310 с.

4. Чопра K., Дас C. Тонкопленочные солнечные элементы. М.: Мир, 1986. 435 с.

5. Bouroushian M., Kosanovic T., Loizos Z., Spyrellis N. Electrochemical Formation of Zinc Selenide From Aqueous Solution // J. Solid State Electrochem. 2002. V. 6(2). P. 272-278.

6. Mahalingam T., Dhanasekaran V., Chandramohan R., Rhee Jin-Koo. Microstructural Properties of Electrochemically Synthesized ZnSe thin Films // J. Mater. Sci. 2012. V. 47(4). P.1950-1957.

7. Remigiusz K., Zabinski P., Fitzner K. Electrodeposition of ZnSe // Electrochimica Acta. 2008. V.53. № 21. P. 6184-6190.

8. Софронов Д.С., Софронова Е.М., Костенюкова Е.И., Стариков В.В., Лебединский А.М., Матейченко П.В. Получение пленок $\mathrm{ZnSe}$ методом гидрохимического осаждения // J. Nano Electron. Phys. 2014. T. 6 (1). C. 01016-1-01016-4.

9. Софронова Е.М., Стариков В.В., Софронов Д.С., Костенюкова Е.И., Лебединский А.М., Матейченко П.В. Оптические и электрические свойства пленок $\mathrm{ZnSe}$, полученных методом гидрохимического осаждения // Неорган. материалы. 2015. Т. 51. № 9. C. $960-966$.

10. Selected powder diffraction data for education (Handbook). Published by the International Centre for diffraction data. Patent USA, 1988. P. 432.

11. Алекперов А.И. Электрохимия селена и теллура // Успехи химии. 1974. Т. 43. № 4. С. 585-611.

12. Sofronov D.S., Sofronova E.M., Kovalenko N.O., Starikov V.V., Gerasimenko A.S., Baumer V.N., Lebedinsky A.M., Matejchenko P.V., Grishina E.V., Lavrynenko S.N., Mamalis A.G. Obtaining a $\mathrm{ZnSe}$ furnace charge from aqueous solution // Nanotechnology Perceptions. 2014. V. 10 (2) P. 154-163.

13. Miller F.A., Charles D., Wilkins H. Infrared Spectra and Characteristic Frequencies of Inorganic Ions Their Use in Qualitative Analysis // Analytical Chem. 1952. V. 24(8). P. 1253-1294.

14. Азаренко Н.А., Литовченко С.В., Неклюдов И.М., Стоев П.И. Коррозия и защита металлов. Ч. 1. Химическая коррозия металлов. Харьков: ХНУ, 2007. $187 \mathrm{c}$. 